\title{
Eosinophil Hematopoietins Antagonize the Programmed Cell Death of Eosinophils Cytokine and Glucocorticoid Effects on Eosinophils Maintained by Endothelial Cell-conditioned Medium
}

Erk Her, Jonathan Frazer, K. Frank Austen, and William F. Owen, Jr. Department of Medicine, Harvard Medical School, and Department of Rheumatology and Immunology, Brigham and Women's Hospital, Boston, Massachusetts 02115

\begin{abstract}
Granulocyte-macrophage colony-stimulating factor (GMCSF) was established as the constitutive and elicited human umbilical vein endothelial cell-derived eosinophil viability-sustaining factor. Stimulation of endothelium cell monolayers with IL-1 $\alpha(5 \mathrm{U} / \mathrm{ml})$ increased the 48-h elaboration of GM-CSF from a mean of 3.2 to a mean of $8.2 \mathrm{pM}(P<0.05)$. Dexamethasone $(100 \mathrm{nM})$ decreased the constitutive GM-CSF elaboration by $49 \%(P<0.001)$ but did not diminish production by IL-1 $\alpha$ stimulated endothelium. However, eosinophil viability decreased by $21 \%$ in dexamethasone-pretreated IL-1 $\alpha$-stimulated endothelial cell-conditioned medium $(P<0.05)$, which suggested viability antagonism by glucocorticoids. After $24 \mathrm{~h}$ of culture, eosinophil viability for replicate cells in enriched medium alone or with 1 pM GM-CSF decreased from means of 43 and $75 \%$ to means of 21 and $54 \%$, respectively, when dexamethasone was included $(P<0.05)$. However, 10 pM GM-CSF, IL-3, or IL-5 protected the cells against dexamethasone and against endonuclease-specific DNA fragmentation. In this model system of eosinophil-tissue interactions, dexamethasone prevents the endothelial cells from inducing a pathobiologic phenotypic change in the eosinophil by suppression of GMCSF elaboration to concentrations that are not cytoprotective. Cytokine priming by GM-CSF, IL-3, or IL-5 may account for the differential responsiveness of select eosinophilic disorders to glucocorticoids. (J. Clin. Invest. 1991. 88:1982-1987.) Key words: apoptosis • cytokine $\bullet$ cell culture $\bullet$ DNA • interleukin
\end{abstract}

\section{Introduction}

The survival in vitro of normodense human peripheral blood eosinophils for at least $14 \mathrm{~d}$ requires their continued exposure to one of three hematopoietins whose genes are located on the short arm of the fifth chromosome: granulocyte-macrophage colony-stimulating factor (GM-CSF), ${ }^{1}$ IL-3, or IL-5 (1-4). During the interval of cytokine exposure, the eosinophils undergo an alteration in their physical and functional properties characterized by a decrement in their relative centrifugation density in discontinuous gradients of metrizamide (hypo-

Address reprint requests to William F. Owen, Jr., M.D., The Seeley G. Mudd Building, Room 610, 250 Longwood Ave., Boston, MA 02115. Received for publication 19 February 1991 and in revised form 25 July 1991.

1. Abbreviation used in this paper: GM-CSF, granulocyte-macrophage colony-stimulating factor.

J. Clin. Invest.

(c) The American Society for Clinical Investigation, Inc. $0021-9738 / 91 / 12 / 1982 / 06 \$ 2.00$

Volume 88, December 1991, 1982-1987 dense), augmented antibody-dependent cytotoxicity against the Schistosoma mansoni schistosomula, enhanced elaboration of $\mathrm{LTC}_{4}$ and generation of superoxide when stimulated with $N$-formyl-L-methionyl-L-leucyl-L-phenylalanine, and increased size of the cell-associated proteoglycans $(1-3,5,6)$. Previously, we have reported that both bovine pulmonary artery or human umbilical vein endothelial cells constitutively elaborate a soluble activity that, in a manner comparable to that of the three eosinophil hematopoietins, maintains the ex vivo viability of normodense eosinophils and primes them for enhanced $\mathrm{LTC}_{4}$ generation in response to stimulation with calcium ionophore $A 23187(1-3,7)$. We now report that both the constitutively elaborated eosinophil viability-sustaining activity and the activity from IL- $1 \alpha$-stimulated endothelial cells are GM-CSF, and that this eosinophil hematopoietin along with IL-3 and IL-5 maintains eosinophil viability by preventing endonuclease-specific DNA degradation.

Although the constitutive elaboration of GM-CSF was attenuated by pretreatment of the endothelium with dexamethasone, such pretreatment had no effect on the IL- $1 \alpha$-stimulated endothelium. Dexamethasone had an antagonistic effect on the viability of normodense eosinophils cultured in the presence of suboptimal concentrations of GM-CSF, IL-3, and IL-5. In contrast, $10 \mathrm{pM}$ GM-CSF, IL-3, and IL-5, concentrations that are optimal for the 7-d survival of eosinophils in vitro and for converting them to the functionally primed hypodense phenotype (1-3), fully protected the eosinophils from the effect of dexamethasone. Thus, the previous findings of enhanced eosinophil viability and augmentation of effector function during $7 \mathrm{~d}$ of culture with GM-CSF, IL-3, and IL-5 (1-3) are extended by the demonstration of a rapid onset cytoprotective action against programmed cell death and against dexamethasonemediated cytotoxicity. Furthermore, the therapeutic role of dexamethasone in reducing or eliminating the hypodense eosinophil phenotype, which has been associated with certain human eosinophilic disorders, could involve both decreased production of GM-CSF and the consequent diminution in GMCSF-mediated cytoprotection of eosinophils.

\section{Methods}

Culture and stimulation of endothelial cells. Human umbilical vein endothelial cells (passage 13, CRL-1730; American Type Culture Collection, Rockville, MD) were plated onto 75-ml plastic flasks (CoStar, Cambridge, MA) and were cultured in enriched medium (MCDB 110 [Sigma Chemical Co., St. Louis, MO] supplemented with $25 \mathrm{mM}$ Hepes, $0.1 \%$ sodium bicarbonate, $2 \mathrm{mM}$ L-glutamine, $100 \mathrm{U} / \mathrm{ml}$ penicillin, $100 \mu \mathrm{g} / \mathrm{ml}$ streptomycin, $100 \mu \mathrm{M}$ minimal essential amino acids, $10 \%$ FBS [Gibco, Grand Island, NY], $30 \mu \mathrm{g} / \mathrm{ml}$ endothelial cell growth factor [Boehringer-Mannheim Biochemicals, Indianapolis, IN], and $100 \mu \mathrm{g} / \mathrm{ml}$ pork heparin) (7). The medium was changed every other day. Just before the cells achieved confluence, they were passaged by incubating the monolayer with $0.05 \%$ trypsin containing $0.53 \mathrm{mM}$ 
EDTA in $\mathrm{HBSS}$ without calcium or magnesium for $5 \mathrm{~min}$ at $37^{\circ} \mathrm{C}$. The cells were washed, resuspended in enriched medium, and plated onto $35-\mathrm{mm}$ plastic tissue culture dishes $\left(\sim 2.5 \times 10^{5}\right.$ cells/dish). All experiments were performed after contact-inhibited endothelial cell monolayers had become confluent. For all experiments, passages 14-19 were used. Endothelial cell-conditioned medium was harvested after a 48-h incubation with or without recombinant human IL- $1 \alpha(5 \mathrm{U} / \mathrm{ml}$; Genetics Institute, Cambridge, MA) (8) in the presence or absence of dexamethasone (100 nM to $10 \mu \mathrm{M}$ dexamethasone 21-phosphate; Sigma Chemical Co., St. Louis, MO). Conditioned medium was filtered in a sterile manner through a $0.45-\mu \mathrm{m}$ filter and stored at $-70^{\circ} \mathrm{C}$ until tested.

Isolation of eosinophils and maintenance in culture. Normodense human peripheral blood eosinophils were isolated by the discontinuous metrizamide gradient technique $(1-3,7)$. The peripheral blood was obtained from nine donors, none of whom was ingesting aspirin, other nonsteroidal antiinflammatory drugs, or corticosteroids. Normodense eosinophils of $>80 \%$ purity, as determined by Wright's and Giemsa staining, were used for each experiment. Residual contaminating erythrocytes were eliminated by hypotonic lysis, and neutrophils were the sole contaminating leukocyte. The initial cell viability was $>98 \%$, and the viability of the eosinophils in culture was again determined by their ability to exclude trypan blue $(1-3,7)$. Freshly isolated eosinophils were suspended in enriched medium $\left(10^{6}\right.$ cells $\left./ \mathrm{ml}\right)$, and $100-\mu$ l cell suspensions were placed into 96-well flat-bottomed microtiter plates (CoStar) containing $100 \mu \mathrm{l}$ of enriched medium alone, enriched medium supplemented with defined concentrations of human recombinant GM-CSF, IL-3, or IL-5 (all provided by Genetics Institute), or various concentrations of endothelial cell-conditioned medium. In some experiments, $100 \mathrm{nM}$ dexamethasone, prednisolone, hydrocortisone, and testosterone (all from Sigma Chemical Co.) were included in the eosinophil cultures. The plates were maintained at $37^{\circ} \mathrm{C}$ in a $5 \%$ $\mathrm{CO}_{2}$ atmosphere.

Antibody neutralization of cytokine activity. For some experiments, various dilutions of a rabbit neutralizing polyclonal antibody against human GM-CSF (Genzyme Corp., Boston, MA) or against human IL-3 (Genetics Institute), or a rat monoclonal antibody against mouse IL-5 (purified from clone TRFK-5 and provided by R. L. Coffman of DNAX Research Institute, Palo Alto, CA) conjugated to cyanogen bromide-activated Sepharose CL-4B beads (Sigma Chemical Co.) were preincubated for $1-2 \mathrm{~h}$ at $37^{\circ} \mathrm{C}$ with conditioned medium or recombinant cytokine before the eosinophils were added $(9,10)$. In experiments with anti-IL-5, the beads were sedimented by centrifugation of the incubation mixture at $250 \mathrm{~g}$ for $5 \mathrm{~min}$ at $4^{\circ} \mathrm{C}$, and the supernatant was used for subsequent experiments.

Quantitation of GM-CSF levels in conditioned medium. Conditioned medium was prepared from the endothelial cells alone or after stimulation with IL- $\alpha$ in the presence or absence of dexamethasone. GM-CSF concentrations in these media were determined by a solid phase ELISA (Genzyme Corp.), which uses the multiple antibody sandwich technique. GM-CSF was detectable in the linear portion of the binding curve at concentrations from 7 to $65 \mathrm{pM}$ using biosynthetic (recombinant) standards. No immunologic cross-reactivity was noted for IL-3 or IL-5 at concentrations of 67 and 77 pM, respectively.

Analysis of DNA fragmentation by eosinophils. Freshly isolated normodense eosinophils (1.0-1.5 $\times 10^{6}$ cells) were incubated for various intervals in enriched medium alone, or in enriched medium containing 10 pM GM-CSF, 10 pM IL-3, 10 pM IL-5, 1,000 U/ml tumor necrosis factor- $\alpha$ (TNF $\alpha$ ), $100 \mathrm{nM}$ dexamethasone, or combinations of cytokine and glucocorticoid, at $37^{\circ} \mathrm{C}$ in a $5 \% \mathrm{CO}_{2}$ atmosphere. The eosinophils were counted, pelleted at $4^{\circ} \mathrm{C}$, resuspended in $20 \mu$ l of $10 \mathrm{mM}$ EDTA and $50 \mathrm{mM}$ Tris- $\mathrm{HCl}, \mathrm{pH} 8.0$, containing $0.5 \%$ sodium lauryl sarkosinate and $0.5 \mathrm{mg} / \mathrm{ml}$ proteinase $\mathrm{K}$, and incubated for 60 min at $50^{\circ} \mathrm{C}(11)$. A $10-\mu l$ portion of $0.5 \mathrm{mg} / \mathrm{ml}$ ribonuclease $\mathrm{A}$ was added to each sample, and the samples were incubated for $60 \mathrm{~min}$ more at $50^{\circ} \mathrm{C}$. Then, $10 \mu \mathrm{l}$ of $10 \mathrm{mM}$ EDTA, pH 8.0 , containing $0.25 \%$ bromophenol blue and $40 \%$ sucrose were mixed with each DNA extract. The individual DNA extracts were loaded into the wells of a $2 \%$ agarose gel containing $3 \mu \mathrm{g} / \mathrm{ml}$ of ethidium bromide. As a DNA size standard, $2 \mu$ l of PhiX 174 RF DNA-Hae III digest (New England Biolabs, Beverly, MA) was loaded into adjacent wells. Electrophoresis was performed at $4^{\circ} \mathrm{C}$ in $90 \mathrm{mM}$ Tris- $\mathrm{HCl}$, pH 8.3, containing $90 \mathrm{mM}$ boric acid and $2.5 \mathrm{mM}$ EDTA until the marker dye had migrated $6-8 \mathrm{~cm}$. The gel was visualized and photographed in UV light with Polaroid type 57 high-speed film, and a negative image was obtained from the positive.

Statistical analysis. The statistical significance of differences between sample means for each set of eosinophils was based upon comparisons as determined by the two-tailed Student's $t$ test.

\section{Results}

Effect of endothelial cell-conditioned medium on eosinophil viability. The 3-d survival of normodense peripheral blood eosinophils increased in a dose-dependent manner from $21 \pm 6 \%$ ( $m e a n \pm S E M, n=5$ ) for cells maintained in enriched medium alone to a maximum of $52 \pm 5 \%$ for eosinophils maintained in $50 \%$ constitutive endothelial cell-conditioned medium $(P$ $<0.001$ ). The $3-\mathrm{d}$ survival of eosinophils maintained in $1-50 \%$ IL- $1 \alpha$-stimulated endothelial cell-conditioned medium was significantly increased $(P<0.05)$ at all concentrations above their survival in constitutive endothelial cell-conditioned medium alone. The 3-d viability of eosinophils maintained in 50\% IL-1 $\alpha$-stimulated endothelial cell-conditioned medium was increased from $25 \pm 2 \%$ to a maximum of $73 \pm 0 \%(n=5)$. An $\mathrm{ED}_{50}$ of 5 and $3 \%$ conditioned medium was observed for replicate eosinophils cultured for $3 \mathrm{~d}$ in constitutive-derived endothelial cell-conditioned medium and IL- $1 \alpha$-stimulated endothelial cell-conditioned medium, respectively. The supplementation of enriched medium with an equivalent concentration of IL-1 $\alpha$ alone did not increase eosinophil viability above that observed with enriched medium alone $(25 \pm 2 \%$, $n=5$, and $21 \pm 6 \%, n=5$, respectively) $(P>0.2)$.

Identification of the constitutive and IL-1 $\alpha$-stimulated endothelial cell-derived eosinophil viability-sustaining activity. In preliminary experiments, it was determined that anti-GMCSF at a concentration of $100 \mu \mathrm{g} / \mathrm{ml}$ completely neutralized the eosinophil viability-sustaining activity of $10 \mathrm{pM}$ GM-CSF (9). At $100 \mu \mathrm{g} / \mathrm{ml}$, anti-GM-CSF did not cross-react with IL-3 and IL-5. Replicate samples of normodense eosinophils were cultured for $3 \mathrm{~d}$ in enriched medium alone, or in enriched medium supplemented with $10 \mathrm{pM}$ GM-CSF, $50 \%$ endothelial cell-conditioned medium, or 50\% IL-1 $\alpha$-stimulated endothelial cell-conditioned medium. Eosinophil viability was $10 \pm 4$, $74 \pm 4,44 \pm 4$, and $68 \pm 5 \%($ mean \pm SEM, $n=3)$, respectively. Preincubation of these same media with $100 \mu \mathrm{g} / \mathrm{ml}$ of antiGM-CSF decreased eosinophil survival to $7 \pm 2,10 \pm 8,12 \pm 8$, and $12 \pm 9 \%$, respectively $(P<0.05$ compared with cultures without antibody) (Fig. 1). In two experiments in which the preincubation of $10 \mathrm{pM}$ IL-3 with anti-IL-3 (1:250 final dilution) decreased the 3-d survival of replicate eosinophils from 82 and $56 \%$ with IL-3 alone to 12 and $10 \%$, respectively, the survival of eosinophils maintained in $25 \%$ endothelial cell-conditioned medium was unaffected. In similar fashion, preabsorption by anti-IL-5 $(20 \mu \mathrm{g} / \mathrm{ml})$ of $1 \mathrm{pM}$ IL-5 decreased eosinophil viability from 63 and $63 \%$, to 3 and $5 \%$, respectively. However, the viability of eosinophils maintained with $25 \%$ endothelial cell-conditioned medium was unaffected by preabsorption.

Influence of dexamethasone on GM-CSF elaboration by endothelial cells. As quantitated by ELISA, the constitutive generation of GM-CSF by endothelial cells over $48 \mathrm{~h}$ was $3.2 \pm 0.8$ 


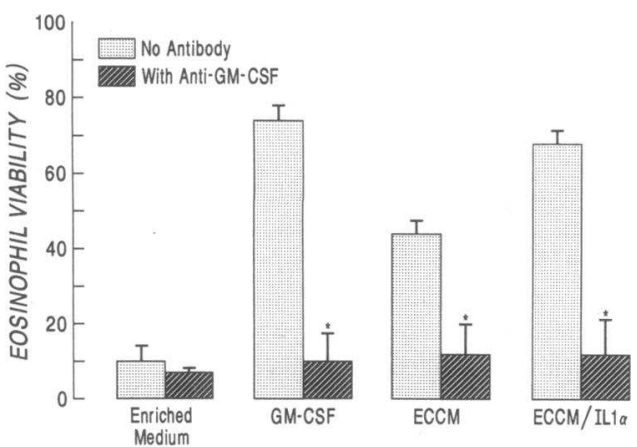

Figure 1. Neutralization by anti-GM-CSF of the eosinophil viabilitysustaining activity obtained from enriched medium alone, $10 \mathrm{pM}$ recombinant GM-CSF, 50\% constitutive endothelial cell-conditioned medium (ECCM), and 50\% IL- $\alpha$-stimulated endothelial cell-conditioned medium (ECCM/IL $1 \alpha$ ). The percentage of viable eosinophils after $3 \mathrm{~d}$ of culture is expressed as mean \pm SEM for three experiments. *Statistically significant decrease in eosinophil viability for cells cultured with neutralizing antibody compared with replicate cells cultured without antibody $(P<0.05)$.

pM (mean $\pm \mathrm{SEM}, n=4)$. After stimulation of the endothelial cells with $5 \mathrm{U} / \mathrm{ml}$ of IL- $1 \alpha$, GM-CSF elaboration increased to $8.2 \pm 0.9 \mathrm{pM}(n=4)$. Treatment of replicate unstimulated endothelial cell cultures with $100 \mathrm{nM}$ dexamethasone for $48 \mathrm{~h}$ reduced constitutive GM-CSF elaboration by $49 \pm 5 \%(n=4)$ to $1.7 \pm 0.6 \mathrm{pM}(P<0.001)$. In contrast, dexamethasone $(100 \mathrm{nM})$ treatment for $48 \mathrm{~h}$ of replicate IL-1 $\alpha$-stimulated endothelial cells did not result in a reduction in GM-CSF elaboration, which was maintained at $7.8 \pm 0.8 \mathrm{pM}$. Increasing the concentration of dexamethasone to $10 \mu \mathrm{M}$ did not result in a decrease in the augmented quantity of GM-CSF elaborated by the IL$1 \alpha$-stimulated endothelial cells.

Influence of dexamethasone on eosinophil viability. The viability of eosinophils cultured for $3 \mathrm{~d}$ in enriched medium alone, in endothelial cell-conditioned medium, and in IL- $1 \alpha$-stimulated endothelial cell-conditioned medium was $22 \pm 5,58 \pm 1$, and $75 \pm 1 \%$, respectively $(n=4)$ (Fig. 2). The pretreatment of replicate endothelial cell monolayers for $24 \mathrm{~h}$ with $100 \mathrm{nM}$

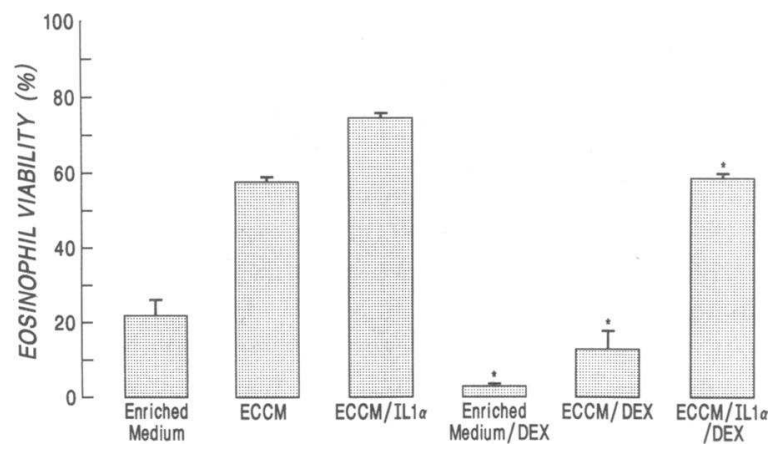

Figure 2. Influence of dexamethasone (DEX) on the 3-d eosinophil viability-sustaining activity observed for enriched medium alone or for $50 \%$ endothelial cell-conditioned medium (ECCM) collected 48 $\mathrm{h}$ after various treatments. The results expressed are the mean \pm SEM of four experiments. *Statistically significant decrease in eosinophil viability for replicate cells cultured in 48-h conditioned medium from $24 \mathrm{~h}$ dexamethasone-pretreated endothelial cultures, compared with untreated cultures $(P<0.01)$. dexamethasone decreased the viability of replicate eosinophils to $3 \pm 1,14 \pm 4$, and $59 \pm 1 \%$, respectively $(P<0.05$ for differences in eosinophil viability for replicate cell cultures with or without dexamethasone).

The negative effect on eosinophil viability of IL- $1 \alpha$-stimulated endothelial cell-conditioned medium prepared in the presence of dexamethasone was inconsistent with the failure of this glucocorticoid to suppress the stimulated release of GMCSF. Thus, it seemed likely that dexamethasone had an additional direct effect on eosinophils. Replicate eosinophils were cultured for up to $3 \mathrm{~d}$ with or without $100 \mathrm{nM}$ dexamethasone in enriched medium alone or medium supplemented with 1 and $10 \mathrm{pM}$ GM-CSF. By $24 \mathrm{~h}$ of culture, and extending to $3 \mathrm{~d}$ for cells cultured with 1 pM GM-CSF, statistically significant differences in eosinophil viability were observed for cells that were cultured with dexamethasone in enriched medium alone or with $1 \mathrm{pM}$ GM-CSF as compared to replicate cells cultured without dexamethasone (Fig. 3). The 24-h viability of replicate eosinophils cultured in enriched medium alone was reduced from $43 \pm 6 \%(n=3)$ to $21 \pm 7 \%$ with dexamethasone $(P<0.05)$, and for eosinophils cultured in $1 \mathrm{pM}$ GM-CSF was reduced from $75 \pm 2 \%(n=3)$ to $54 \pm 6 \%$ with dexamethasone $(P<0.05)$. In contrast, the viability of eosinophils cultured in 10 pM GMCSF was unaffected by the inclusion of dexamethasone (Fig. 3).

The glucocorticoid-induced antagonism of eosinophil viability augmented by GM-CSF was evaluated further by culturing replicate normodense eosinophils with incremental concentrations of IL-3 (0.1-100 pM) and IL-5 (0.01-10 pM) in the presence and absence of $100 \mathrm{nM}$ dexamethasone. Similar to GM-CSF, dexamethasone-induced viability antagonism at $3 \mathrm{~d}$ was abolished by culturing the eosinophils with higher concentrations of cytokine (Fig. 4).

To determine the steroid specificity of dexamethasone-induced antagonism of the eosinophil hematopoietins, replicate eosinophils were cultured for $3 \mathrm{~d}$ with $1 \mathrm{pM}$ GM-CSF in the presence and absence of $100 \mathrm{nM}$ dexamethasone, prednisolone, hydrocortisone, and testosterone. In comparison to dexamethasone, which decreased eosinophil viability at $3 \mathrm{~d}$ from $42 \pm 3 \%$ to $8 \pm 2 \%$ (assigned a value of 1.0 ), prednisolone, hydrocortisone, and testosterone decreased the eosinophil viabilitysustaining activity of $1 \mathrm{pM}$ GM-CSF by the relative values of $0.7 \pm 0.2,0.2 \pm 0.2$, and $0 \pm 0$, respectively $(n=3)$.

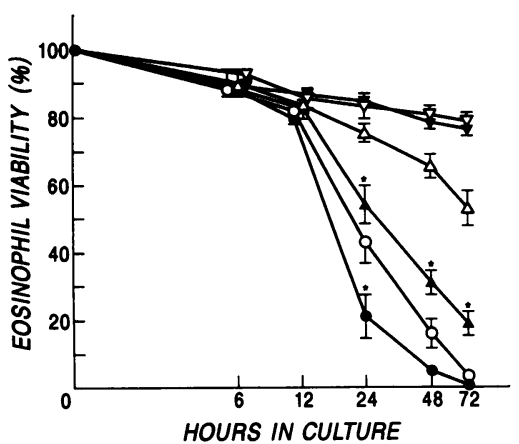

Figure 3. Effect of dexamethasone on the viability of replicate eosinophils cultured in enriched medium alone $(\bullet)$, or in medium supplemented with $1 \mathrm{pM}$ (A) or 10 pM (v) GMCSF. Replicate eosinophils, which were cultured under the same conditions in the absence of dexamethasone, are represented by the corresponding open symbol. The results are expressed as the mean \pm SEM of three experiments. *Statistically significant decrease in the viability of eosinophils cultured in the presence of dexamethasone, as compared to replicate cells cultured under the same conditions without dexamethasone $(P<0.05)$. 

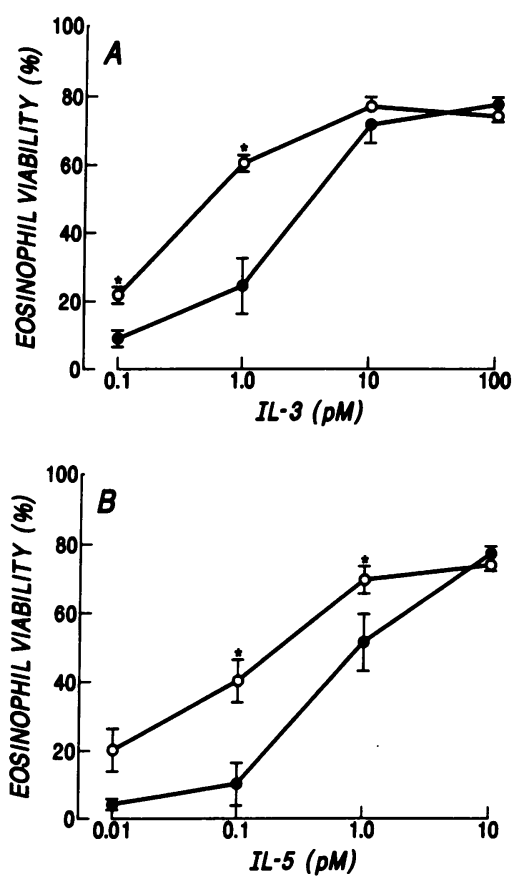

Figure 4. Influence of dexamethasone on IL-3 $(A)$ and IL-5 $(B)$ augmented eosinophil survival after $3 \mathrm{~d}$ of culture Solid symbols correspond to eosinophils cultured in the presence of $100 \mathrm{nM}$ dexamethasone; open symbols correspond to replicate eosinophils cultured in the absence of dexamethasone. *Statistically significant decrease in the viability of eosinophils cultured in the presence of dexamethasone, as compared to replicate cells cultured under the same conditions without dexamethasone $(P<$ 0.05 ).
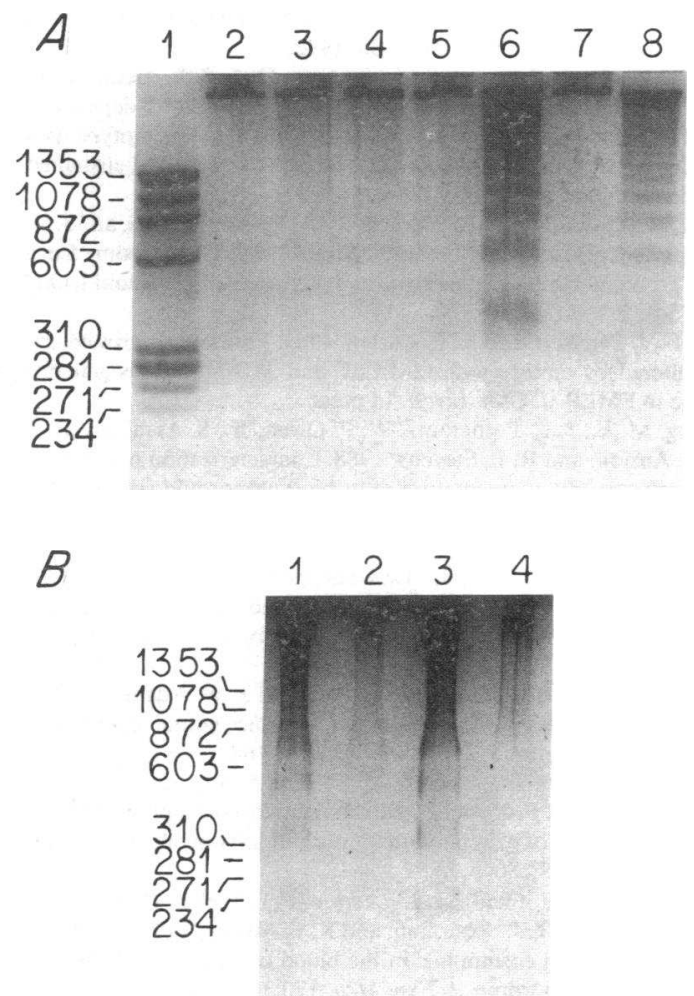

Figure 5. Influence of GM-CSF on eosinophil DNA fragmentation. $(A)$ DNA was extracted from $1.5 \times 10^{6}$ freshly isolated eosinophils (lane 2) and replicate cells that were cultured for 10,20, and $38 \mathrm{~h}$ in enriched medium alone (lanes 4,6 , and 8 , respectively) or for the same intervals with $10 \mathrm{pM} \mathrm{GM-CSF}$ (lanes 3, 5, and 7, respectively). Lane $l$ was loaded with DNA of standard sizes (PhiX174 RF DNAHae III digest). (B) DNA was extracted from $1.5 \times 10^{6}$ replicate eosinophils that were cultured for $24 \mathrm{~h}$ in enriched medium alone (lane 1), or with $10 \mathrm{pM} \mathrm{GM-CSF}$ (lane 2), $100 \mathrm{nM}$ dexamethasone alone (lane 3), or GM-CSF and dexamethasone (lane 4).
Influence of GM-CSF, IL-3, and IL-5 on DNA fragmentation of eosinophils. As visualized by agarose gel electrophoresis, DNA obtained from freshly isolated eosinophils was intact. However, by $20 \mathrm{~h}$ of culture in enriched medium alone, the eosinophil DNA was degraded with a characteristic apoptotic "ladder" pattern of fragmentation in which prominent fragments of $<1,000 \mathrm{bp}$ were observed with decrements of $\sim 200$ bp (Fig. $5 \mathrm{~A}$ ). DNA extracts obtained from replicate eosinophils cultured in $10 \mathrm{pM}$ GM-CSF revealed a marked reduction in DNA fragmentation $(n=2)$. Furthermore, $10 \mathrm{pM} \mathrm{GM-CSF}$ attenuated DNA fragmentation in eosinophils cultured for 24 $\mathrm{h}$ even in the presence of $100 \mathrm{nM}$ dexamethasone $(n=4)$ (Fig. 5 $B$ ). After $24 \mathrm{~h}$ of culture in the absence of GM-CSF, DNA fragmentation was of such magnitude that it was difficult to define additional fragmentation due to the presence of dexamethasone. The capacity of eosinophil-directed hematopoietic cytokines to prevent DNA fragmentation in normodense eosinophils was examined by culturing replicate eosinophils for $24 \mathrm{~h}$ with enriched medium alone, $10 \mathrm{pM}$ IL-3, $10 \mathrm{pM}$ IL-5, and $1,000 \mathrm{U} / \mathrm{ml}$ TNF $\alpha$. Prominent DNA fragmentation characteristic of apoptosis was observed in eosinophils cultured in medium alone or with TNF $\alpha$, but was absent in the eosinophils cultured with IL-3 and IL-5 (data not shown).

\section{Discussion}

The in vitro viability and the physical and functional phenotype of human peripheral blood eosinophils are regulated by the action of GM-CSF, IL-3, and IL-5 $(1-3,5,6)$. In the idiopathic hypereosinophilic syndrome and the tryptophan-associated eosinophilia/myalgia syndrome, the presence of hypodense eosinophils in the blood is associated with excessive serum levels of IL-5 $(9,10,12)$. Because T lymphocytes produce each of these hematopoietins (13), the $T$ cell has been the focus for IL-5 elaboration in these hypereosinophilic states (14-16). When stimulated with the appropriate cytokines, both human umbilical vein endothelial cells $(8,17,18)$ and human fibroblasts (19) elaborate GM-CSF. Because unstimulated human endothelial cells elaborate a soluble activity capable of regulating the viability and phenotype of human eosinophils (7), we sought to characterize this activity, and to utilize this model cell system to determine the endothelial cell-mediated interactions of IL- $1 \alpha$ and dexamethasone on eosinophil viability.

Both the constitutive and the IL- $1 \alpha$-stimulated endothelial cell-derived eosinophil viability-sustaining activity acted in a dose-dependent manner. Based upon complete antibody neutralization with monospecific antibody, this activity was demonstrated to be GM-CSF (Fig. 1). Antibodies against IL-3 and IL-5 had no effect. As quantitated by ELISA, the mean 48-h constitutive generation of GM-CSF was $3.2 \mathrm{pM}$, and with IL$1 \alpha$ stimulation, this level was increased 2.5-fold. Monocytederived IL-1 was shown to augment the generation of endothelial cell-derived eosinophil viability-sustaining activity (20), and GM-CSF mRNA and protein increase when endothelial cells are stimulated with IL-1 $(8,17,18)$.

Because glucocorticoids are commonly used in the therapy of disorders associated with tissue and peripheral blood eosinophils (12), we examined the capacity of dexamethasone to attenuate the generation of GM-CSF by the endothelium and to influence eosinophil viability. At a concentration of dexamethasone $(100 \mathrm{nM})$ that decreased the constitutive generation of 
GM-CSF by endothelial cells by $\sim 50 \%$, the effect on IL- $1 \alpha$ stimulated augmented elaboration of GM-CSF was negligible. Increasing the concentration of dexamethasone to $10 \mu \mathrm{M}$ did not diminish IL- $\alpha$-elicited GM-CSF levels. However, even when the GM-CSF concentration was not reduced by dexamethasone, the viability of eosinophils maintained with dexamethasone was significantly diminished (Fig. 2). Thus, as has been previously suggested, dexamethasone appeared to have an antagonistic effect on the cytokine-mediated maintenance of eosinophil viability (20). Additionally, dexamethasone had an indirect effect to diminish eosinophil viability by a decrease in the constitutive production of GM-CSF by endothelial cells.

Dexamethasone accelerated the loss of viability of eosinophils maintained in enriched medium alone or in enriched medium supplemented with 1 pM GM-CSF, a suboptimal concentration as defined by its capacity to extend eosinophil viability ex vivo and to induce the acquisition of the hypodense eosinophil phenotype $(1,5)$. If the eosinophils were cultured with a concentration of GM-CSF that was optimal for eliciting these effects $(10 \mathrm{pM})(1,5,21)$, their viability in vitro was unaffected by the inclusion of dexamethasone (Fig. 3). In a similar manner, optimal concentrations of IL-3 and IL-5 $(2,3,5)$ were observed to block the effect of dexamethasone (Fig. 4). The effect of dexamethasone was demonstrated to be specific for the glucocorticoids based upon the absence of an effect by the androgenic steroid testosterone, and a rank order of potency of dexamethasone, prednisolone, and hydrocortisone in this assay that was similar to their antiinflammatory potency.

Glucocorticoid-induced lymphocytolysis is preceded by a pattern of DNA cleavage characterized by DNA fragmentation into $\sim 200$-bp multiples $(22,23)$, and this "ladder" pattern of fragmentation is associated with endonuclease-specific programmed cell death (apoptosis) $(11,24,25)$. The sizes of the DNA fragments from cytokine-deprived eosinophils exhibited the same $\sim 200$-bp "ladder" pattern of DNA degradation (Fig. $5 \mathrm{~A}$ ). However, eosinophil DNA was protected from this process by the inclusion of GM-CSF during the culture, even in the presence of dexamethasone (Fig. $5 B$ ). Both IL-3 and IL-5 were also capable of preventing programmed cell death in normodense eosinophils. In contrast, TNF $\alpha$, which is capable of priming select eosinophil functions (21) but is without eosinophil viability-sustaining activity (2), was unable to prevent endonuclease-specific DNA degradation. Thus, the three hematopoietins with the capacity to maintain the ex vivo viability of normodense eosinophils, and to convert them to the functionally primed hypodense phenotype, are selectively able to prevent apoptosis. The occurrence of programmed cell death after the withdrawal of IL-3 from hematopoietic precursor cell lines has been described (26). However, the protective role of these hematopoietins against programmed cell death in eosinophils has not been previously recognized.

The present study of a model cell system identifies GMCSF as the constitutive and IL- $1 \alpha$-stimulated endothelial cellderived eosinophil viability-sustaining factor. Glucocorticoids suppress the constitutive production of GM-CSF by the endothelium and antagonize the viability sustaining effect of suboptimal concentrations of GM-CSF. However, glucocorticoids do not suppress IL- $1 \alpha$-elicited GM-CSF, and these higher concentrations of GM-CSF, and IL-3 and IL-5, prevent glucocorticoid-mediated antagonism of eosinophil viability. These findings demonstrate that, in addition to mediating a phenotypic change of mature normodense eosinophils to the primed hypodense phenotype which occurs over several days in culture (13,5 ), GM-CSF, IL-3, and IL-5 have an acute cytoprotective effect for normodense eosinophils which is associated with the prevention of programmed cell death (apoptosis). Thus, stimulus-elicited cytokine production by another cell type might provide concentrations of these eosinophil-directed hematopoietins which are sufficiently great to produce steroid-resistant eosinophils. The resulting eosinophils would be capable of a conversion to the highly pathobiologic hypodense phenotype, and this sequence of events may explain the differential responsiveness of select eosinophilic disorders to intervention with corticosteroids. $^{2}$

\section{Acknowledgments}

We are grateful to Dr. R. J. Soberman for his helpful discussions.

This work was supported in part by grants AI-22531, AI-22563, AI-23401, AR-38638, HL-36110, and RR-05950 from the National Institutes of Health, and in part by the Hyde and Watson Foundation.

\section{References}

1. Owen, W. F., Jr., M. E. Rothenberg, D. S. Silberstein, J. C. Gasson, R. L. Stevens, K. F. Austen, and R. J. Soberman. 1987. Regulation of human eosinophil viability, density, and function by granulocyte/macrophage colony-stimulating factor in the presence of 3T3 fibroblasts. J. Exp. Med. 166:129-141.

2. Rothenberg, M. E., W. F. Owen, D. S. Silberstein, J. Woods, R. J. Soberman, K. F. Austen, and R. L. Stevens. 1988. Human eosinophils have prolonged survival, enhanced functional properties, and become hypodense when exposed to human interleukin 3. J. Clin. Invest. 81:1986-1992.

3. Rothenberg, M. E., J. Petersen, R. L. Stevens, D. S. Silberstein, D. T. McKenzie, K. F. Austen, and W. F. Owen, Jr. 1989. Interleukin-5-dependent conversion of normodense human eosinophils to the hypodense phenotype uses 3T3 fibroblasts for enhanced viability, accelerated hypodensity, and sustained antibody-dependent cytotoxicity. J. Immunol. 143:2311-2316.

4. LeBeau, M. M., R. S. Lemons, R. Espinosa, R. A. Larson, N. Arai, and J. D. Rowley. 1989. Interleukin- 4 and interleukin- 5 map to human chromosome 5 in a region encoding growth factors and receptors and are deleted in myeloid leukemias with a del (5q). Blood. 73:647-650.

5. Owen, W. F., J. Petersen, and K. F. Austen. 1991. Eosinophils primed and phenotypically altered by culture with GM-CSF and 3T3 fibroblasts generate $\mathrm{LTC}_{4}$ in response to FMLP. J. Clin. Invest. In press.

6. Rothenberg, M. E., J. L. Pomerantz, W. F. Owen, Jr., S. Avraham, R. J. Soberman, K. F. Austen, and R. L. Stevens. 1988. Characterization of a human eosinophil proteoglycan and augmentation of its biosynthesis and size by interleukin 3, interleukin 5, and granulocyte/macrophage colony-stimulating factor. J. Biol. Chem. 263:13901-13908.

7. Rothenberg, M. E., W. F. Owen, Jr., D. S. Silberstein, R. J. Soberman, K. F. Austen, and R. L. Stevens. 1987. Eosinophils cocultured with endothelial cells have increased survival and functional properties. Science (Wash. DC). 237:645647.

8. Broudy, V. C., K. Kaushansky, J. M. Harlan, and J. W. Adamson. 1987. Interleukin 1 stimulates human endothelial cells to produce granulocyte/macrophage colony-stimulating factor. J. Immunol. 129:464-468.

9. Owen, W. F., J. Petersen, D. M. Sheff, R. D. Folkerth, R. J. Anderson, J. M. Corson, A. L. Sheffer, and K. F. Austen. 1990. Hypodense eosinophils and interleukin 5 activity in the blood of patients with the eosinophilia-myalgia syndrome. Proc. Natl. Acad. Sci. USA. 87:8647-8651.

10. Owen, W. F., M. E. Rothenberg, J. Petersen, P. F. Weller, D. Silberstein, A. L. Sheffer, R. L. Stevens, R. J. Soberman, and K. F. Austen. 1989. Interleukin 5 and phenotypically altered eosinophils in the blood of patients with the idiopathic hypereosinophilic syndrome. J. Exp. Med. 170:343-348.

11. Smith, C. A., G. T. Williams, R. Kingston, E. J. Jenkinson, and J. T.

2. While the manuscript for this article was in review, two additional groups of investigators reported that GM-CSF is the constitutive eosinophil viability-sustaining activity derived from human endothelial cells and human bronchial epithelium, and that glucocorticoids antagonize the viability effects of this cytokine in the presence of suboptimal concentrations $(27,28)$. Programmed cell death was not examined in either paper. 
Owen. 1989. Antibodies to CD3-T-cell receptor complex induce death by apoptosis in immature T-cells in thymic cultures. Nature (Lond.). 337:181-183.

12. Enokihara, H., H. Kajitani, S. Nagashima, S. Tsunogake, N. Takano, K Saito, S. Furusawa, H. Shishido, Y. Hitoshi, and K. Takatsu. 1990. Interleukin 5 activity in sera from patients with eosinophilia. Br. J. Haematol. 75:458-462.

13. Silberstein, D. S., K. F. Austen, and W. F. Owen, Jr. 1989. Hemopoietins for eosinophils: glycoprotein hormones that regulate the development of inflammation in eosinophilia-associated disease. Hematol. Oncol. Clin. N. Am. 3:511 533.

14. Raghavacher, A, S. Fleischer, N. Frickhofen, $\mathrm{H}$.Heimpel, and B. Fleischer. 1987. T lymphocyte control of human eosinophil granulopoiesis: clonal analysis in an idiopathic hypereosinophilic syndrome. J. Immunol. 139:3753-3758.

15. Enokihara, H., S. Furusawa, H. Nakakubo, H. Kajitani, S. Nagashima, K. Saito, H. Shishido, Y. Hitoshi, K. Takatsu, T. Noma, A. Shimizu, and T. Honjo 1989. T cells from eosinophilic patients produce interleukin- 5 with interleukin-2 stimulation. Blood. 73:1809-1813.

16. Limaye, A. P., J. S. Abrams, J. E. Silber, E. A. Ottesen, and T. B. Nutman. 1990. Regulation of parasite-induced eosinophilia: selectively increased interleukin 5 production in helminth-infected patients. J. Exp. Med. 172:399-402.

17. Sieff, C. A., S. Tsai, and D. V. Faller. 1987. Interleukin 1 induces cultured endothelial cell production of granulocyte-macrophage colony-stimulating factor. J. Clin. Invest. 79:48-51.

18. Kaushansky, K. 1989. Control of granulocyte-macrophage colony-stimulating factor production in normal endothelial cells by positive and negative regulatory elements. J. Immunol. 143:2525-2529.

19. Zucali, J. R., C. A. Dinarello, D. J. Oblon, M. A. Gross, L. Anderson, and R. S. Weiner. 1986. Interleukin 1 stimulates fibroblasts to produce granulocytemacrophage colony stimulating activity and prostaglandin E2. J. Clin. Invest. $77: 1857-1863$.
20. Lamas, A., G. V. Marcotte, and R. P. Schleimer. 1989. Human endothelial cells prolong eosinophil survival. Regulation by cytokines and glucocorticoids. J. Immunol. 142:3978-3984.

21. Silberstein, D. S., W. F. Owen, J. C. Gasson, J. F. DiPersio, D. W. Golde J. C. Bina, R. J. Soberman, K. F. Austen, and J. R. David. 1986. Enhancement of human eosinophil cytotoxicity and leukotriene synthesis by biosynthetic (recombinant) granulocyte-macrophage colony-stimulating factor. J. Immunol. 137:3290-3294.

22. Cohen, J. J., and R. C. Duke. 1987. Glucocorticoid activation of calcium dependent endonuclease in thymocyte nuclei leads to cell death. $J$. Immunol. 132:38-42.

23. Compton, M. M., and J. A. Cidlowski. 1986. Rapid in vivo effects of glucocorticoids on the integrity of rat lymphocyte genomic deoxyribonucleic acid. Endocrinology. 118:38-45.

24. Shi, Y., M. G. Szalay, L. Paskar, M. Boyer, B. Singh, and D. R. Green. 1990. Activation-induced cell death in $\mathrm{T}$ cell hybridomas is due to apoptosis: morphologic aspects and DNA fragmentation. J. Immunol. 144:3326-3333.

25. Mangan, D. F., G. R. Welch, and S. M. Wahl. 1991. Lipopolysaccharide, tumor necrosis factor- $\alpha$, and IL- $1 \beta$ prevent programmed cell death (apoptosis) in human peripheral blood monocytes. J. Immunol. 146:1541-1546.

26. Williams, G. T., C. A. Smith, E. Spooncer, T. M. Dexter, and D. R. Taylor. 1990. Haemopoietic colony stimulating factors promote cell survival by suppressing apoptosis. Nature (Lond.). 343:76-79.

27. Lamas, A. M., O. G. Leon, and R. P. Schleimer. 1991. Glucocorticoids inhibit eosinophil responses to granulocyte-macrophage colony-stimulating factor. J. Immunol. 147:254-259.

28. Cox, G., T. Ohtoshi, C. Vancheri, J. A. Denburg, J. Dolovich, J. Gauldie, and M. Jordana. 1991. Promotion of eosinophil survival by human bronchia epithelial cells and its modulation by steroids. Am. J. Respir. Cell Mol. Biol. $4: 525-531$. 